\title{
Why Did Abolishing Fees Not Increase Public School Enrollment in Kenya?
}

\section{Tessa Bold, Mwangi Kimenyi, Germano Mwabu, and Justin Sandefur}

\begin{abstract}
A large empirical literature has shown that user fees signicantly deter public service utilization in developing countries. While most of these results reflect partial equilibrium analysis, we find that the nationwide abolition of public school fees in Kenya in 2003 led to no increase in net public enrollment rates, but rather a dramatic shift toward private schooling. Results suggest this divergence between partial- and general-equilibrium effects is partially explained by social interactions: the entry of poorer pupils into free education contributed to the exit of their more affluent peers.
\end{abstract}




\title{
Why Did Abolishing Fees Not Increase Public School Enrollment in Kenya?
}

\author{
Tessa Bold \\ Mwangi Kimenyi \\ Germano Mwabu \\ Justin Sandefur
}

\begin{abstract}
We acknowledge the enormous assistance of Charles Obiero and Samuel Nthenge of the Ministry of Education and Godfrey Ndeng'e and Samuel Kipruto of the Kenyan National Bureau of Statistics in assembling the data sources used here. This document is an output of research funding from the UK Department for International Development (DFID) as part of the iiG, a research programme to study how to improve institutions for pro-poor growth in Africa and South-Asia. The views expressed here are not necessarily those of DFID. We have benefited from comments from Gabriel Demombynes, Charles Kenny, Karega Mutahi, Lant Pritchett, Jakob Svensson, and participants at iiG events in Nairobi (Institute for Economic Affairs), Kampala (Economic and Policy Research Council), and Oxford (Centre for the Study of African Economies).

CGD is grateful for contributions from the the William and Flora Hewlett Foundation in support of this work.
\end{abstract}

Tessa Bold et al. "Why Did Abolishing Fees Not Increase Public School Enrollment in Kenya?” CGD Working Paper 271. Washington, D.C.: Center for Global Development. http://www.cgdev.org/content/publications/detail/1425590

Center for Global Development 1800 Massachusetts Ave., NW Washington, DC 20036

202.416.4000

(f) 202.416 .4050

www.cgdev.org
The Center for Global Development is an independent, nonprofit policy research organization dedicated to reducing global poverty and inequality and to making globalization work for the poor. Use and dissemination of this Working Paper is encouraged; however, reproduced copies may not be used for commercial purposes. Further usage is permitted under the terms of the Creative Commons License.

The views expressed in CGD Working Papers are those of the authors and should not be attributed to the board of directors or funders of the Center for Global Development. 


\section{Introduction}

A recent wave of randomised trials in developing countries has shown demand for public services to be highly price elastic, with even low user fees dramatically reducing utilisation (Michael Kremer \& Alaka Holla 2009). Critics have questioned the relevance of these partial-equilibrium exercises for policymaking, on the grounds that they ignore potential general equilibrium effects (Daron Acemoglu 2010). In the education context, a large literature on school segregation and sorting has shown that relatively privileged parents may seek to disassociate themselves from marginal social groups (Thomas J. Nechyba 2006, Sarah Reber 2011). In this paper we explore whether these social interactions generate general equilibrium effects which might obscure or reverse the downward-sloping demand curves anticipated by partial equilibrium analysis of fee abolition.

In January 2003, the Kenyan government announced the abolition of all school fees in public primary schools. We estimate the effect of this nationwide reform by comparing public and private schools at primary and secondary level, before and after the reform - analogous to a triple-differences estimator.

Confirming anecdotal reports by James Tooley (2009) we find that FPE was an ineffective tool to increase school participation. Instead, net enrollment in government primary schools remained unchanged over the ten-year period from 1997 to 2006. Meanwhile, both net enrollment and fee rates in private schools more than doubled.

We interpret this perverse demand response to a fall in price as prima facie evidence that FPE led to a (perceived) decline in public school quality. There are at least three potential mechanisms that may explain this shift in perceived quality, all of which would result only from a price decrease affecting a large number of children and might elude detection in small-scale experiments: $(i)$ an influx of new students and concomitant deterioration in the composition of pupils; (ii) a change in underlying school productivity or value added, possibly due to a change in the accountability framework under free service provision; and (iii) changes in overall financial resources due to lost fee revenue. By linking FPE to reduced school quality each of these mechanisms may obscure the downward-sloping demand curves predicted by partial equilibrium analysis.

Our core empirical model in Section 5 focuses on the response of enrollment to the first channel, testing whether pupils who exited public school did so in response to new entrants. To overcome the observational equivalence of local spillover and unobserved school quality effects (cf. G Ellison \& E Glaeser 1997), we follow Patrick Bayer \& Christopher Timmins (2007) in using exogenous char- 
acteristics of schooling options not chosen - in our application the test scores of nearby private schools for children enrolled in government school and vice versa - as an instrument. Under the assumption of 'no quality spillovers' between schools, these attributes will drive enrollment choices but be uncorrelated with unobserved school quality.

The results of this enrollment choice model suggest that the exit of affluent pupils in response to marginal entrants was sufficiently large to explain the entire shift in demand (and perceived school quality) under FPE in favor of private schools.

This result is corroborated by simple descriptive statistics in Section 4 showing that public school funding did not decline under FPE as lost fee revenue was more than offset by new central-government grants. While we present no direct measures of school value-added or the second channel listed above, it is noteworthy that our empirical model is able to explain the paradoxical shifts in enrollment without recourse to the hypothesis of declining school value-added.

Our paper relates to a recent literature from field experiments in developing countries which have established significantly negative price-elasticities of demand (David Evans, Michael Kremer \& Muthoni Ngatia 2009, Jessica Cohen \& Pascaline Dupas 2010, Nava Ashraf, James Berry \& Jesse Shapiro 2010). These same studies have shown that free provision presents few trade-offs in terms of allocative efficiency or psychological effects on "ownership" that may encourage recipients to make better use of a costly product. Relating this to FPE in Kenya, we argue that stable public enrollment rates are consistent with a negative price-elasticity of demand. Similarly we find no evidence of direct effects of free provision on school value-added as one might associate with efficiency or ownership channels.

A separate literature has examined large-scale reforms to user fees in education. Results mainly suggest a positive effect on school enrollment as a whole, though our evidence suggests these results may obscure important differences in the role of public and private schools in these reforms. Klaus Deininger (2003) shows that the introduction of free schooling in Uganda was associated with a large increase in enrollment when aggregating both public and private schools ${ }^{1}$ Positive enrollment effects from fee abolition are also documented for Colombia (Felipe Barrera-Osorio, Leigh L. Linden \& Miguel Urquiola 2007) and Cambodia (Maria Cheung, Andreas Madestam \& Jakob Svensson 2011), again without

\footnotetext{
${ }^{1}$ Free provision in Uganda also appears to be have been progressive, with poorer households more likely to take advantage of free schools - a finding confirmed in our results below and by Milu Charles Muyanga, John Olwande, Esther Mueni \& Stella Wambugu (2010) using a different data set than ours for Kenya.
} 
distinguishing the role of public and private schools. Also worth noting is that the large effects on school enrollment documented under conditional cash transfer programs such as PROGRESA in Mexico (T. Paul Schultz 2004) correspond to a change in the opportunity cost of both public and private schools.

The findings here for Kenya are novel in that we focus on fee abolition that was exclusive to public schools, but find that this reform did not significantly raise public enrollment. To our knowledge, ours is the first study to note a link from free public education to the emergence of private schools. While we focus on enrollment here, the explanation we provide for why FPE did not lead to a significant increase in net public enrollment is consistent with recent research on standardised test scores in Kenya. First, our evidence suggests reduced demand for public schools was driven by affluent flight from marginal peers, rather than reduced school value added. In line with this, Adrienne Lucas \& Isaac Mbiti (2011) also examine the Kenyan experience and find a small, negative effect of FPE on test scores in public schools that appears to be driven by changes in pupil composition. Second, enrollment choices in favor of private schools appear to be driven by demand for quality education. Consistent with this finding, Tessa Bold, Mwangi Kimenyi, Germano Mwabu \& Justin Sandefur (2011) find a large, causal test-score gap between Kenyan public and private schools.

\section{Background and Data}

\subsection{Policy background}

Prior to the introduction of FPE, non-salary expenditure for schools was obtained through events known as harambee, which aimed to raise financial and in-kind contributions for education and development from local communities. While in principle voluntary, in practice children whose parents had not made any harambee contributions were suspended from school (Mary Kay Gugerty \& Edward Miguel 2005).

Under the FPE policy, government primary schools previously responsible for raising funds locally to pay for classroom maintenance, desks, books and other non-salary expenditures, are prohibited from collecting revenue. Instead, each school now receives a central government grant twice per year to cover these non-salary costs.

In contrast to the changes that occurred in the financing of non-salary education expenditure, the system of teacher employment and local school governance has remained the same. All teachers are centrally recruited, hired and fired, 
assigned and reassigned and paid by the Teacher Service Commission, a subsidiary of the Ministry of Education located in Nairobi. At the local level, school management committees, consisting of parents, the head teacher, and district education board officials, have official governing authority for each school.

\subsection{Data}

We draw on two broad types of data: household survey data, which underlies the core of our analysis, and school-level administrative data. Both data sets span the period before and after the enactment of FPE.

\subsubsection{Household survey data}

The analysis of education expenditure and enrollment is based on two consecutive, nationally-representative, cross-sectional, household surveys conducted by the Kenya National Bureau of Statistics. The first is the 1997 Welfare Monitoring Survey (WMS), which includes a sample of 10,874 households - including 13,639 children of primary-school age - interviewed roughly five years prior to the introduction of FPE. The second round of data is taken from the 2006 Kenya Integrated Household Budget Survey (KIHBS), spanning 13,212 households (with 14,610 children of primary-school age), interviewed three academic years after FPE had been implemented.

These data sets are well-suited to our needs in that they include comparable modules on school enrollment from before and after the onset of FPE, distinguishing between public and private school attendance. Use of integrated household surveys with detailed consumption and expenditure information allows us to highlight changes in the socioeconomic composition of public and private school enrollment over this period. In addition, specific questions on education expenditure provide the basis for examining pre-reform variation in government school fees and secular changes in the equilibrium price of private schools. The clustered nature of the household survey samples - providing information on multiple households in the catchment area of a given public or private school - is central to our empirical strategy to estimate social interaction effects, including the impact of school crowding on the incentive to send one's child to a government or private school. 


\subsubsection{School-level administrative data}

We use test-score data from the Kenya Certificate of Primary Education (KCPE) exam as a proxy for school quality. The KCPE exam is standardised nationwide, administered at the end of primary school by the Kenya National Examination Council, and covers English, Kiswahili, math, science and history. The art and business exams introduced in 2001 are excluded here to maintain comparability over time. Our combined test-score data set constitutes a panel of all public and private primary schools in Kenya, for each year from 1998 to 2006.

Because we use the test scores as one determinant of school choice, we seek to construct a proxy of the quality of all public and private schools available to a given pupil. We use administrative districts as a conservative proxy of this choice set and collapse test scores to district averages, separately for public and private schools. The household survey data and administrative test-score data are matched at the district level for use in the enrollment model below.

\section{Enrollment and expenditure changes since FPE}

In this section, we document the effect of FPE on school enrollment and expenditure. Because the FPE reform was instituted simultaneously nationwide, we base our inferences about the effect of FPE on a comparison of the trajectories of enrollment and expenditure across two dimensions: public versus private primary schools, and primary versus secondary schools. We begin by laying out the basic empirical facts and conclude the section with a discussion of what these facts imply about shifts in demand and the perceived quality of public primary schools under FPE.

\subsection{Enrollment patterns}

Did the abolition of fees lead to an increase in primary public enrollment? The top panel of Figure 1 shows net enrollment rates for public and private primary schools before and after FPE. Contrary to expectations, FPE was not associated with an increase enrollment in public primary schools. In fact, net enrollment in public primary schools was essentially unchanged over the ten-year period spanning the onset of FPE. Instead, it was the private sector that saw a large influx of students - nearly tripling in size between 1997 and 2006.

For comparison purposes, we also plot changes in the net enrollment rate in the secondary sector in the bottom panel of Figure 1 . Since fees were maintained 


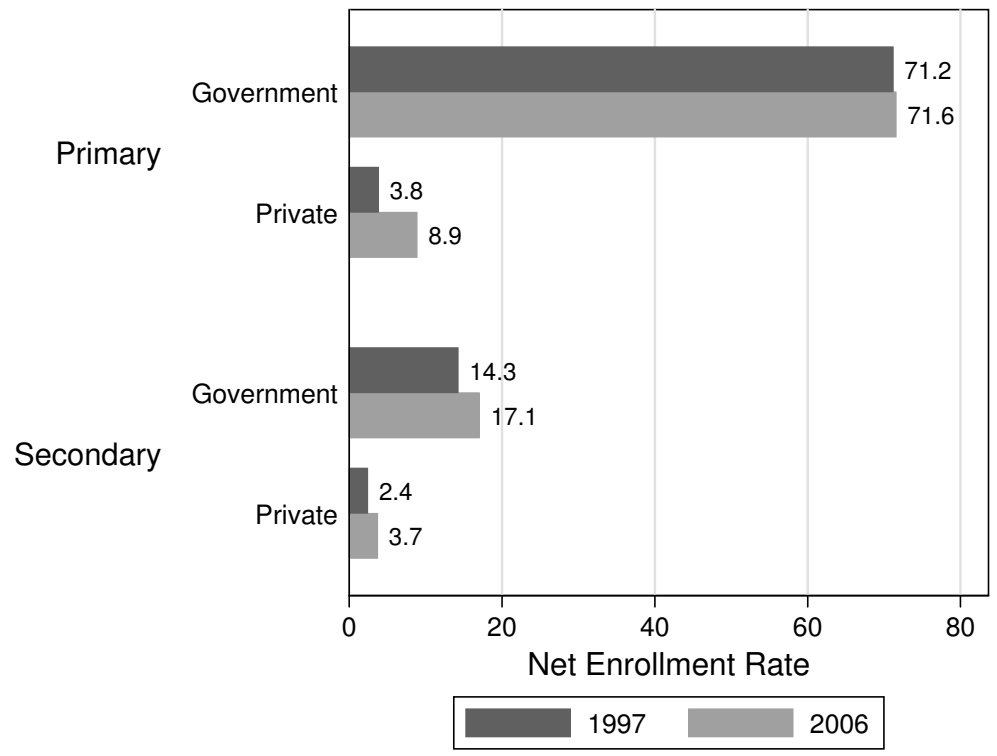

Figure 1: Net enrollment rates, by sector, before and after FPE, based on household survey data (WMS \& KIHBS) 
in the secondary sector throughout the period, this serves as a control group of sorts. In contrast to the primary sector, net enrollment in both the public and private system increased. The fact that the majority of the increase in secondary private enrollment is explained by the general trend in secondary enrollment, gives us some confidence that it was FPE, and not other factors, which introduced a unique wedge between public and private enrollment in the primary sector.

Table 1 presents gross and net enrollment rates in public and private schools before and after FPE disaggregated by parental education. The disaggregated numbers show that the negligible growth in aggregate enrollment masks substantial movement in and out of public primary schooling. enrollment of less educated households (primary education or less) in the public sector increased significantly, whereas more educated households left the public sector. Conversely, increases in enrollment in the private sector were largely concentrated among the well-educated. That is, FPE broadened access to primary schooling on the one hand, while contributing to increased segregation between public and private primary schools on the other.

\subsection{Expenditure patterns}

Next, we examine the price effect of the introduction of FPE. In other words, did FPE successfully reduce the cost of schooling for children enrolled in public primary school, and how did fees in private schools respond? To examine this question, we simply look at household expenditure on education before and after FPE, distinguishing between fees and other expenditure, and contrasting the public and private system. We estimate these costs as follows

$$
\begin{aligned}
\operatorname{Exp}_{i t} & =\gamma_{p 0} \operatorname{Pri}_{i t}+\gamma_{p 1}\left(\operatorname{Pri}_{i t} \times \mathrm{FPE}\right) \\
& +\gamma_{s 0} \operatorname{Sec}_{i t}+\gamma_{s 1}\left(\operatorname{Sec}_{i t} \times \mathrm{FPE}\right)+u_{i t}
\end{aligned}
$$

where $\operatorname{Exp}_{i t}$ is a measure of the education expenditure for household $i$ in period $t$, Pri $_{i t}$ and $\mathrm{Sec}_{i t}$ measure the number of household members enrolled in primary and secondary education respectively. Note that equation (1) contains no constant and the dummy variable for FPE is only included as an interaction term. Thus the $\gamma_{p 0}$ and $\gamma_{s 0}$ can be read directly as the average level of spending per pupil before FPE, and $\gamma_{p 1}$ and $\gamma_{s 1}$ as the change in spending per pupil under FPE. 


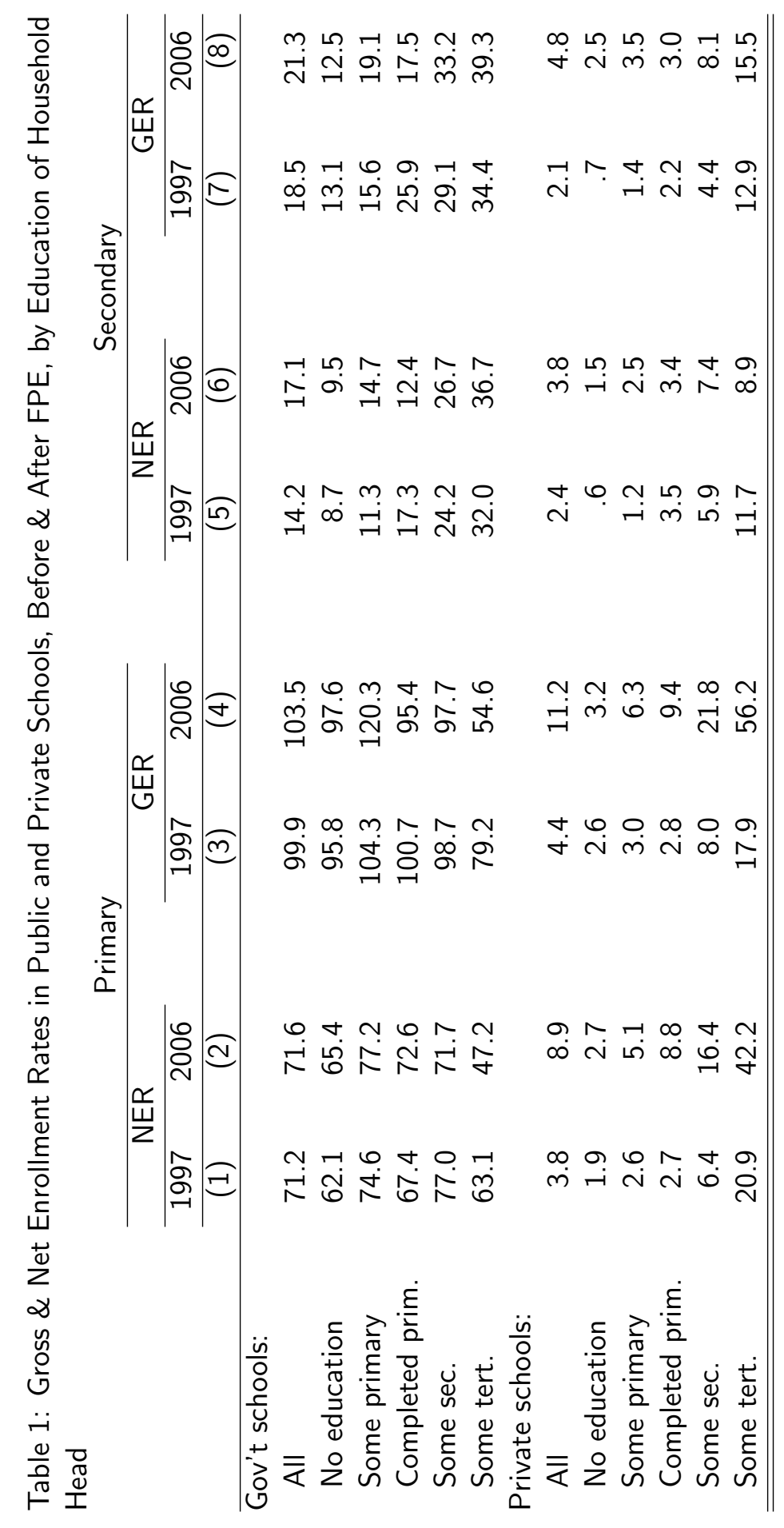


Columns (1) and (2) of Table (2) show the composition of real annual household expenditure on private and public primary schooling both before and after FPE. The main result to take away from Table 1 is that per-pupil expenditure on public primary schooling has effectively halved since the introduction of FPE and the expenditure on fees has effectively gone to zero, while the expenditure on private primary schooling per pupil has more than doubled in the same time span. All these effects are significant at the $1 \%$ level. Therefore the introduction of FPE has had the expected price effect. Combined with the enrollment trends since FPE, this implies that aggregate expenditure on public schooling has fallen, while total expenditure on private schooling has increased.

For comparison purposes, columns (3) and (4) report the results from the same analysis applied to expenditure on secondary education. Since secondary education was funded by parental fees during the entire period, this can be regarded as a placebo experiment. As can be seen from column (3) and (4), expenditure on secondary education is high, but the relative difference between private and public expenditure is much smaller than in the primary sector both before and after the introduction of FPE. Moreover, total expenditure on secondary schooling has dropped in both sectors over the period (by $20 \%$ in terms of total expenditure and by $50 \%$ in terms of fees in the public sector. Expenditure in the private sector has also dropped, although the effect is not significant). Hence, it is not the case that we are merely observing an overall increase in demand and thus price for private schooling. Rather, this increase is restricted to the primary sector, which has been subject to FPE.

\subsection{Inferring school quality from changes in quality and price}

The shifts in enrollment and fee levels documented above provide clues about changes in school quality under FPE.

Consider the anticipated effects of free primary education on public and private primary school enrollment in a simple supply and demand model. Assume the following: households choose between government and private schools; an individual child must be enrolled in either one system or the other; demand curves are downward-sloping and supply curves upward-sloping for both public and private education.

Now consider the anticipated effect of the introduction of free primary education within this model. Fee abolition yields a perfectly elastic supply curve for government schools at zero price. Enrollment in public school increases and private enrollment falls. This decline in demand for private schooling would 
Table 2: Household educational expenditure

\begin{tabular}{ccccc}
\multicolumn{2}{c}{ Exp. on Primary } & & \multicolumn{2}{c}{ Exp. on Secondary } \\
\cline { 1 - 2 } \cline { 5 - 6 } All & Fees & & All & Fees \\
$(1)$ & $(2)$ & & $(3)$ & $(4)$ \\
\hline
\end{tabular}

Kids in pub. prim.

$638.24 \quad 217.15$

$(19.69)^{* * *} \quad(14.50)^{* * *}$

Kids in priv. prim.

$3592.08 \quad 2440.98$

$(640.44)^{* * *} \quad(574.23)^{* * *}$

FPE $\times$ Kids in pub. prim. $\quad-297.09-197.30$

$(26.63)^{* * *} \quad(19.32)^{* * *}$

FPE $\times$ Kids in priv. prim. $\quad 4325.59 \quad 2642.72$

$(962.48)^{* * *} \quad(822.85)^{* * *}$

Kids in pub. sec.

$10192.02 \quad 7496.12$

$(501.25)^{* * *} \quad(459.64)^{* * *}$

Kids in priv. sec.

$15933.68 \quad 13289.38$

$(4419.98)^{* * *} \quad(4268.23)^{* * *}$

FPE $\times$ Kids in pub. sec.

$-1984.66-3659.26$

$(600.33)^{* * *} \quad(496.41)^{* * *}$

FPE $\times$ Kids in priv. sec.

$-215.22-3234.19$

$(5242.75) \quad(4849.94)$

Obs. $\quad 17,238 \quad 17,238 \quad 17,238 \quad 17,238$

The dependent variable is total annual household educational expenditure in 1997 Kenyan Shillings. (1 USD $\equiv$ KES 54 circa June, 1997.) In columns 1 and 2 the dependent variable includes only expenditure on primary education, and in columns 3 and 4 only on secondary education. Columns 1 and 3 include all categories of educational expenditure available in both surveys (i.e., fees, books, uniforms, board, and transport) for the relevant education level. Columns 2 and 4 are restricted to fees only. The FPE variable takes a value of one in 2006 and zero in 1997. Independent variables labeled "Children in ..." measure the total number of children in the household enrolled in a given type of school. The sample is restricted to households that have at least one child in either primary or secondary school. Numbers in parentheses report heteroskedasticity-robust standard errors. 
reduce the equilibrium price of private schools.

The actual shifts in enrollment and fees observed in the data are quite opposite to these predictions. In the public system, the quantity demanded remained unchanged in response to a price decrease - with some socio-economic groups even decreasing their demand, while in the private system both prices and quantities increased dramatically. This constellation of price and quantity shifts can be entirely explained by a sharp downward shift in the demand for public schooling and an increase in the demand for private schooling after FPE.

We take this apparent shift in demand as prima facie evidence that the (perceived) quality of public primary education declined under FPE. To corroborate this evidence, in the following sections we explore possible mechanisms that might link FPE to reduced school quality.

\section{Funding}

The first potential mechanism linking FPE to school quality noted in the introduction was a change in physical, financial or human resources within schools. A reduction in per-pupil resources in public primary schools after FPE could produce a decline in perceived school quality and, in turn, explain the failure of net enrollment to respond to a price decrease. This section attempts a reckoning of the net changes in school resources under FPE, combining household data sources on parental contributions with official government data on capitation grants and pupil-teacher ratios.

\subsection{Financial resources}

The fundamental shift in school finance under the FPE reform was the replacement of school fees with a central government grant. On average, did these grants fully compensate for the lost fee revenue?

The FPE grants were equivalent to approximately $\$ 14$ USD per child per annum, deposited in local bank accounts for each school (Gene Sperling 2008). The accounts were to be administered by "school management committees", chaired by the head teacher and including parent representatives. Despite measures to prevent graft inspired in part by the Ugandan experience (Ritva Reinikka \& Jakob Svensson 2004), an external audit of the FPE funds commissioned by the Ministry of Finance in 2009 found enormous shortfalls in actual disbursements. 


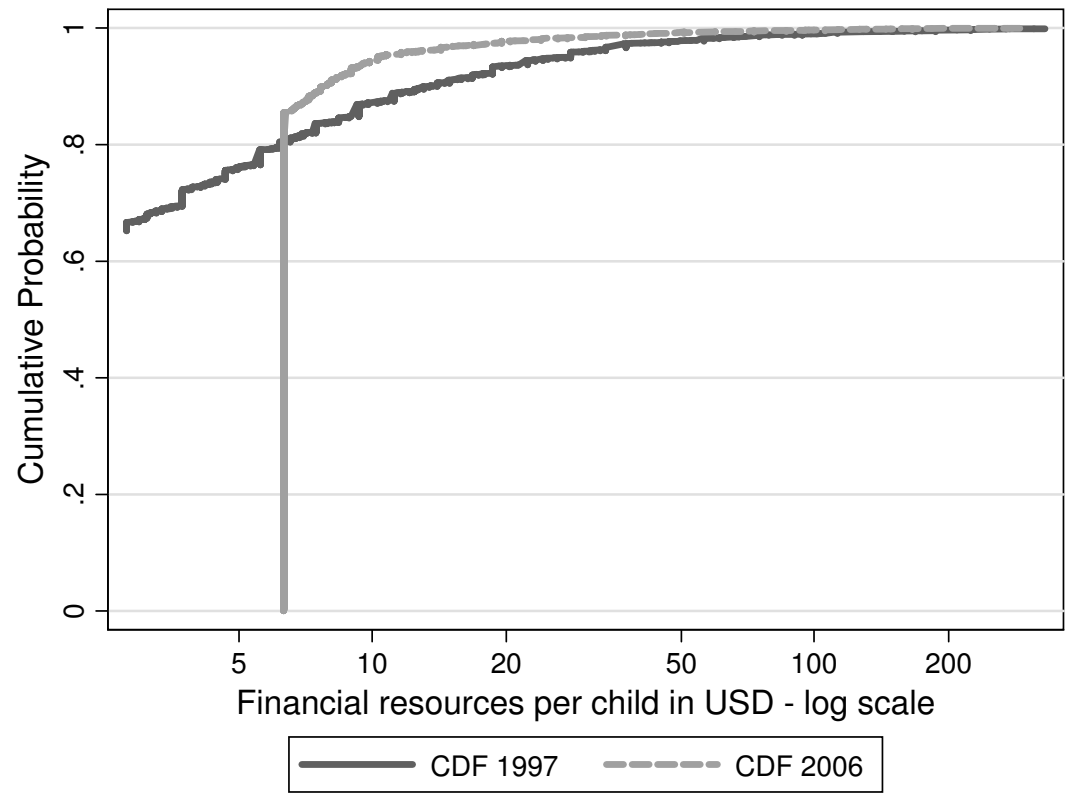

Figure 2: Cumulative distribution function of per pupil funding (fees plus grants) in public primary schools, before and after FPE. 
Actual funds received fell short of the legislated amount in each year audited by approximately 5 to 15\% (Andrew Teyie \& Henry Wanyama 2010).

Despite this leakage, comparing these audit reports to the pre-FPE figures on public school fees from the household survey data in Section 4 , on average the loss in fee revenue was more than offset by the rise in public expenditure through capitation grants. Figure 2 shows the distribution of average financial resources per pupil across Kenyan districts before and after FPE. The unit of observation is a pupil. Per pupil funding in 1997 consists solely of fee revenue, whereas in 2006 it includes fee revenue plus the capitation grant. As seen in the graph, FPE implied a collapse in the variance of the funding distribution. Whereas the 1997 distribution spans the range from zero to $\$ 400$ per annum, the 2006 distribution has a lower bound at the amount of the capitation grant, roughly $\$ 6$ per pupil after leakage. This six-dollar figure represents roughly the 80th percentile of the 1997 funding distribution, indicating that the vast majority of public-school pupils experienced an increase in funding levels.

\subsection{Human resources}

In addition to the capitation grants, the key resource provided to public schools by the central government is teaching staff.

Gross enrollment figures for public schools based on the household survey data (discussed in detail below in section 5) rose from $99.9 \%$ to $103.5 \%$ from 1997 to 2006. Adjusting for population growth, this implies that the total number of pupils in public primary schools rose from 6.63 million in 1997 to 7.56 million in 2006. Unfortunately, data on teacher employment is not available for the same starting point, but administrative records from the Teacher Service Commission show that the total number of teachers employed by the government rose from 133,927 in 2002 - just before the onset of FPE - to 148,845 in 2006. Extrapolating this hiring rate back to 1997 implies a total teacher count of 117,364 . Combining these figures yields a total pupil-teacher ratio for Kenyan public schools that fell during the 10-year period spanning FPE from 56 pupils in 1997 to just under 51 in 2006.

To summarise, for $80 \%$ of primary schools, the loss of fee revenue from FPE was more than compensated by capitation grants. Furthermore, despite the fact that gross enrollment rates rose slightly under FPE, teacher hiring more than kept pace with this increase. Both the financial and human resources available to public schools increased per pupil under FPE. Thus we turn to alternative channels to explain the perceived decline in public school quality 
after the abolition of fees.

\section{Modeling the enrollment choice}

The introduction outlined three avenues by which FPE can affect the quality of schooling and therefore the demand for public versus private school: $(i)$ enrollment decisions of peers, which help determine both expected class size as well as the 'quality' of peers in a given school, ( $i i)$ the underlying quality of the school, capturing the effect of local accountability, unobserved managerial talent, teaching ability, etc., and (iii) school finances. We discussed the third channel in Section 4 . In this section, we examine the roles of class size and peer composition in the decision to enrol in a particular school sector.

We test whether the shift out of public and into private enrollment is explained by social-interaction effects in enrollment. If a large portion of this shift is explained by an adverse reaction to the influx of marginal pupils into public schools, we will interpret this as evidence that the divergence between partial and general equilibrium price elasticities is largely accounted for by compositional effects. On the other hand, failure to find statistically and economically significant social-interaction effects will leave the door open to alternative explanations, including a deterioration in public school value-added after the abolition of fees.

In the rest of this section, we analyze the choice between public, private and no enrollment in a multinomial discrete choice framework and show that the shifts in demand for public and private schooling can be explained almost entirely by changes in class size and the composition of students. In other words, the influx of marginal students documented in the previous section is what caused more affluent students to decrease their demand for public schooling. By accounting for shifts in the demand curve, our results explain how a constant aggregate enrollment rate in response to a price drop is consistent with downward-sloping individual demand curves.

\subsection{Model}

We begin by laying out a simple model of enrollment. Households indexed by $i$, maximise utility by choosing between three schooling options $j=\{N, G, P\}$, i.e. not enrolling $(N)$, attending a government school, $(G)$, or attending a private 
school $(P)$ in schooling market $m=1, \ldots M$ pre- and post-FPE $t=0,1 .^{2}$ Utility is an increasing function of the education acquired, adjusted for quality, subject to the constraint that the cost of education is less than disposable income. The quality of education in turn is decreasing in class size and increasing in the average quality of peers in a given school, which allows for (either positive or negative) enrollment spillovers in a given schooling market $m$. Households choose the schooling option that yields the highest utility.

For the sake of the empirical analysis, we write this as a random additive utility model

$$
U_{i j}^{m}=X_{j, t}^{m} \beta_{0}+\alpha \sigma_{j, t}^{m}+Z_{i, t}^{m} \beta_{j}+\xi_{j, t}^{m}+\varepsilon_{i j, t}^{m}
$$

Utility depends on: (1) observable school quality, $X_{j, t}^{m}$, which is proxied by exam performance in public and private schools in the district; (2) the share of 'marginal' children enrolling in the same school type, $\sigma_{j, t}^{m}$, which is proxied by the share of children from the $25 \%$ least educated households, and (3) a set of individual socio-economic characteristics $Z_{i}$, in particular log food consumption and the years of education of the household head, which reflect household's preferences for education option $j$ in market $m$ as well as their ability to afford it pre-and post FPE. All other school level variables that may affect parental enrollment choices are captured by a choice-specific unobservable $\xi_{j, t}^{m}$. In this context, the most obvious unobservables are the price and value added of the nearby government and/or private primary school. The random component $\varepsilon_{i j}^{m t}$ captures the remaining idiosyncratic heterogeneity in preferences.

Rewriting (3), this model can be estimated using a two-step procedure.

$$
\begin{aligned}
U_{i j}^{m} & =\delta_{j, t}^{m}+Z_{i, t}^{m} \beta_{j}+\varepsilon_{i j, t}^{m} \\
\delta_{j, t}^{m} & =X_{j, t}^{m} \beta_{0}+\alpha \sigma_{j, t}^{m}+\xi_{j, t}^{m}
\end{aligned}
$$

The first step of this procedure consists of estimating the probability that a household enrols in a particular school sector as a function of the individual specific regressors as well as a district-sector-time specific fixed effect. In the second step, we estimate how this fixed value of enrolling in a particular sector is affected by changes in observable school-level attributes and the enrollment behaviour of others.

Estimating the probability that school sector $j$ yields the highest utility to household $i$ is a standard multinomial discrete choice problem (A. Colin Cameron \&

\footnotetext{
${ }^{2}$ It makes sense to model the enrollment decision as taking place in many separate markets, in this case a district, since pupils in Kenya in reality choose among a small number of primary schools in their immediate vicinity.
} 
Pravin K. Trivedi 2005). Assuming that the errors $\varepsilon_{i j}^{m}$ in (3) are iid type I extreme value yields a mixed logit model for the probability of choosing a particular school option as a function of the regressors:

$$
\operatorname{Pr}\left[y_{i}=j\right]=\frac{\delta_{j}^{m t}+Z_{i, t}^{m} \beta_{j}}{\sum_{k=N, G, P}\left(\delta_{k}^{m t}+Z_{i, t}^{m} \beta_{k}\right)}
$$

This model combines features of a conditional and a multinomial logit model, which allows estimation of both school-sector and individual-specific effects (Jeffrey M. Wooldridge 2001).

Having estimated the sector-district-time fixed effects $\delta$ in the first step, the second-step (4) consists simply of a linear regression of the predicted value of enrolling in particular school sector on its various determinants. The goal here is to separate the effect of (positive or negative) spillovers in enrollment $\alpha$ from the unobserved residual demand for a particular school type $\xi_{j, t}^{m}$.

\subsection{Identifying social interactions in enrollment decisions}

In trying to identify the local spillover effect $\alpha$ in (4), we are confronted with the problem that local spillovers cannot readily be distinguished from unobserved group effects (Lawrence Blume \& Steven Durlauf 2005). To paraphrase Ellison \& Glaeser's (1997) 'equivalence theorem' regarding identification of spillovers in an industrial organization context, "the relationship between mean measured levels of [enrollment] and [school] characteristics is the same regardless of whether [enrollment] is the result of [spillovers], [unobserved school characteristics], or a combination of the two." That is, any increase in unobserved school quality will mechanically increase enrollment and therefore the enrollment shares of peers regardless of whether social interactions are present or not - making a separate identification of $\alpha$ and $\xi_{j, t}^{m}$ impossible unless a valid instrument exists.

The characteristics of a valid instrument in this context are that it be correlated with the number of pupils who choose a given school, but not correlated with the unobserved fixed attributes of that school. Bayer \& Timmins (2007) propose a novel strategy to identify social interaction effects by using variation in the underlying choice set of individual agents. This strategy is particularly suited for applications meeting two conditions. First, data are available on a large number of agents endogenously sorting into a fixed set of categories; in our application this involves choosing between government schools, private schools, or not enrolling. Second, data are ideally required on many distinct markets where such sorting occurs; in our application, a market is defined as a district, 
on the assumption that pupils or their parents do not shop for primary schools outside the district where they reside.

The strategy proposed by Bayer \& Timmins (2007) relies on the "internal logic of the choice process itself". The exogenous characteristics of the schooling options not chosen by a given individual - e.g., the characteristics of nearby private schools for students in public school, and vice versa - will provide the content for an instrument under the assumption that there are no quality spillovers between schools. In that case the attributes of the schooling options that were not chosen in each market will contain information that predicts enrollment decisions of an individual's peers, but do not affect the value parents derive from their chosen school sector 3

Following this line of reasoning, any non-linear function of the exogenous characteristics of close-by alternatives to the chosen school type would qualify as a valid instrument. The optimal instrument in this context simply uses the discrete choice model laid out above to predict individual enrollment choices as a function of exogenous individual and alternative-specific characteristics and then averages over all individuals in a market and sector. Specifically, we construct the (non-linear) reduced form prediction of $\sigma$ as:

$$
\tilde{\sigma}_{j, t}^{m, 0}=\int \frac{\exp \left(Z_{i j, t}^{m} \beta_{1}+X_{j, t}^{m} \beta_{0}\right)}{\sum_{k \in m} \exp \left(Z_{i k, t}^{m} \beta_{1}+X_{k, t}^{m} \beta_{0}\right)} d F\left(Z_{i j}^{m}\right)
$$

Close inspection of equation (6) reveals the manner by which effective choice set variation 'switches on' the instrument. If there was only one market (i.e. the whole of Kenya) in which individuals choose to enrol, then the denominator of (6) is a constant. Hence, identification would rely exclusively on the nonlinear transformation of $X_{j, t}^{m} \beta_{0}^{0}$ and is sensitive to misspecification of the utility function and/or error distribution in (3). In contrast, if enrollment choices take place in many distinct markets, the denominator of (6) varies across $m$. In this case, identification is driven by variation in the excluded instruments - not specific functional form assumptions. Simply put: the more choice set variation, the more robust the identification strategy.

The second-stage of the estimation is a simple linear regression with a non-linear

\footnotetext{
${ }^{3}$ In our view the assumption of 'no-spillovers' is a valid first-order approximation to the production of school value. In any case, the instrumentation strategy remains valid even in the case of 'value' spillovers, as long as the set of locations that directly affect the utility an agent derives from his choice is a subset of the location-specific characteristics he considers when making his choice.
} 
IV $\tilde{\sigma} .4$

$$
\hat{\delta}_{j, t}^{m}=X_{j, t}^{m} \beta_{0}+\alpha \tilde{\sigma}_{j, t}^{m}+\xi_{j, t}^{m}
$$

Identifying the local spillover effect $\alpha$ will enable us to estimate the extent to which local spillover effects in enrollment counteract the price effect of FPE.

\subsection{Results}

The results from the first step of the estimation procedure are given in Table 3. where we predict the probability of enrolling in public school, private school or not at all as a function of household socio-economic indicators and a set of district-sector-time dummies.

Column (1) presents the results for primary enrollment choices. The reported effects are equivalent to marginal effects in a standard multinomial logit estimation 5 As anticipated, following FPE, parental education and income are less important in predicting enrollment in public primary school. For the pre-FPE period, there is a positive, and significant association between the household head's education and the child's probability of enrollment in government primary school: every additional year of education increased the probability of public school enrollment by $0.8 \%$. Following FPE, this effect was completely reversed. The results for log-food expenditure are qualitatively similar. Prior to FPE, every one unit increase in log food expenditure increased the probability of attending public school by $1.2 \%$. Following FPE, this effect was more than offset by the significant, negative coefficient on the interaction of log food expenditure and the FPE indicator. In the private sector, there was already a significant relationship between a household's socio-economic standing and enrollment prior to FPE and this became even stronger over time. Before FPE, every additional unit of log-food expenditure increased the probability of enrollment in private school by about $0.09 \%$. Following FPE, this increased to nearly $4 \%$. Similarly, following FPE, each additional year of schooling of the household head increased the probability of enrollment in private school by $1.3 \%$.

\footnotetext{
${ }^{4}$ The parameter vector $\left\{\hat{\delta}, \hat{\beta_{1}}, \hat{\beta_{0}}, \alpha\right\}$ is obtained as follows: $\delta$ and $\beta_{1}$ are generated by estimating the discrete choice model in (5). $\beta_{0}$ and $\alpha$ are the solutions to the non-linear system of equations formed by (6) and (7), which can be found using numerical methods.

${ }^{5}$ The marginal effects of the interaction terms from this discrete choice model, as well as their standard errors, are calculated using the procedures discussed in Chunrong Ai \& Edward Norton (2003), Edward Norton (2004), Thomas DeLeire (2004), and Thomas Cornelissen \& Katja Sonderhof (2009).
} 
Table 3: Enrollment: Multinomial Logit for School Sector Choice Prim.

Sec.

\begin{tabular}{lrr}
\hline Government: & & \\
& & \\
Head's Educ & $\left(0.0082^{*}\right.$ & -0.0052 \\
& $-0.0128 * * *$ & $(0.0074)$ \\
Head's Educ $\times$ FPE & $(0.0041)$ & -0.0100 \\
& 0.0120 & $(0.0098)$ \\
Log Food & $(0.0108)$ & $-0.0813 * * *$ \\
& $-0.0466 * * *$ & $(0.0261)$ \\
Log Food $\times$ FPE & $(0.0134)$ & 0.0125 \\
& & $(0.0283)$ \\
Private: & & \\
& $0.0024^{* * *}$ & 0.0000 \\
Head's Educ & $(0.0004)$ & $(0.0006)$ \\
& $0.0112 * * *$ & 0.0003 \\
Head's Educ $\times$ FPE & $(0.0008)$ & $(0.0001)$ \\
& $0.0088^{* * *}$ & 0.0000 \\
Log Food & $(0.0024)$ & $(0.0002)$ \\
& $0.0399^{*} * *$ & -0.0005 \\
Log Food $\times$ FPE & $(0.0051)$ & $(0.0013)$ \\
\hline Observations & 69513 & 41466 \\
\hline \hline Figures in the table are marginal effects from $(5)$. Standard errors are shown in parentheses. \\
The three choice options are "not enrolled", "government" and "private". "Not enrolled" is \\
the base-category. District-sector-time dummies are included but not shown.
\end{tabular}


It is also instructive to use the underlying multinomial coefficients (not reported in the table) for a direct comparison of how the probability of enrolling in private school relative to public school has changed since FPE. Prior to FPE, one extra year of household head education increased the probability of enrolling in private school relative to the probability of enrolling in public school by $11 \%$. Following FPE, the magnitude of this effect doubled to $22 \%$.

For comparison purposes, we repeat the analysis for secondary schools. If the changes in student composition in the primary sector are in fact due to FPE, then we should not see any similar effects in secondary school. This is indeed the case, as can be seen from column (2) of Table (3), consistent with the patterns observed in the summary statistics in Table (11). The interactions of FPE with socio-economic characteristics are not significant in secondary schools. This failure to find the same systematic pattern of enrollment shifts - of poorer households into government schools and richer households into private schools provides additional confidence that the effects we observe in the primary sector are indeed due to the abolition of school fees in public primary schools rather than an artefact of secular trends independent of the FPE policy.

In sum, the results from estimating the multinomial choice model confirm the descriptive statistics: FPE had a positive effect on equalizing access to government schools as evinced by a negative association between socio-economic background and public enrollment (relative to not enrolling). However, the education system became more stratified following the abolition of fees, as better off households exited to the private sector, which increasingly became a preserve of the affluent.

We now move on to the core of the estimation: controlling for local interactions in the decision to enrol in public or private school. The results from estimating (7) are found in Table (4). The dependent variable is formed by the vector of predicted sector-district-time fixed effects which were estimated as part of the discrete choice model in the previous step. These measure the average value of being enrolled in government or private school in a district before and after FPE controlling for idiosyncratic variation in enrollment choices. We regress the fixed effects on end of primary leaving exam scores, the share of pupils choosing the same school type, and a set of dummies for government and private school as well as their respective interactions with an FPE dummy. The table reports the marginal effects of a change in these regressors on the probability of enrollment.

As anticipated, schools with higher test scores attract more students and after instrumenting the $\sigma$ variable - we find negative local spillover effects, i.e., the share of pupils from less educated households choosing school type 
Table 4: Enrollment: Determinants of the $\delta_{j}$

Government:

KCPE Score

0.0026

$(0.0071)$

$\sigma_{j}^{m}$

$-1.694 * * *$

FPE

$-0.0279 * * *$

$(0.0062)$

Private:

KCPE Score $\quad 0.0006^{* *}$

$(0.0003)$

$\sigma_{j}^{m}$

$-0.3872^{* * *}$

$(0.0301)$

FPE

$0.0638 * *$

$(0.0031)$

Observations

176

The table reports estimates of Equation (4), the second step of the Bayer-Timmins procedure.

Standard errors are reported in parentheses. The dependent variable is the district-sector-time fixed effect from the conditional logit in Table (3). $\sigma_{j}^{m}$ is the instrumented share of pupils from less educated households choosing school type $j$ in market $m$, and KCPE is the average exam score for schools of type $j$ in market $m$. Intercepts included, but not reported.

$j$ has a negative effect on the probability of an additional pupil choosing $j 6$ Unsurprisingly, this effect is much stronger in public schools than in private schools.

Having estimated the local spillover effects consistently, we calculate to what extent social interactions can explain the shifts in enrollment observed in the wake of FPE. The $25 \%$ least educated in our sample increased their enrollment in public school by $4.5 \%$ during the period. Given the coefficient on $\sigma$ in government schools, this implies a decrease in enrollment of almost $7 \%$. Note that this implied effect is larger than the $6.1 \%$ increased in private primary

\footnotetext{
${ }^{6}$ Since this is a non-linear IV problem, it is not possible to separate out the first and secondstage. The coefficients used to predict the enrollment shares include all coefficients in Table 3 as well as those in Table 4 with the exception of the coefficient on $\sigma$ itself.
} 
school enrollment documented in Table 1 . Thus our estimates imply that socialinteraction effects more than explain the shift in the demand toward private primary education in Kenya in the wake of FPE 7

To summarise, basic summary statistics show that the net enrollment rate for government primary schools stagnated under FPE. In this section we have shown that the failure of a price decrease to stimulate a demand increase is related to the change in the composition of peers in public schools. While we have not addressed other channels directly in this section, we note that this socialinteraction effect is sufficiently strong to explain the seemingly counter-intuitive enrollment patterns observed after the abolition of school fees - without positing any decline in underlying school value added.

\section{Conclusion}

The first central finding of this paper is that the abolition of user fees for government primary schools in Kenya in 2003 did not significantly increase net enrollment in public schools. Comparing public and private schools at the primary and secondary level, before and after the Free Primary Education reform, we find that the abolition of user fees shifted demand toward private schooling, evinced by a simultaneous surge in private primary-school enrollment and fee levels.

In attempting to explain this unanticipated demand response, we show that public primary-school funding did not decline in the wake of FPE. The loss in fee revenue to public schools was more than offset by central government capitation grants.

What did change in response to FPE was the socio-economic composition of pupils in public schools. FPE was successful in improving access to education for pupils from poorer households. In contrast, more affluent households became more likely to send their children to private primary schools, leading to increased socio-economic segregation within the school system.

\footnotetext{
${ }^{7}$ Note that the marginal effect of FPE on public school enrollment remains negative in Table 4 after controlling for social interactions. Although occasionally advocated in an earlier literature on mediation in causal chains (Reuben M. Baron \& David A. Kennedy 1986), it is inappropriate to gauge the degree to which social interactions mediate the effect of FPE by their ability to 'knock out' the latter variable from this regression, particularly in an IV context (Donald P. Green, Shang E. Ha \& John G. Bullock 2010, Kosuke Imai, Luke Keele, Dustin Tingley \& Teppei Yamamoto 2011).
} 
The core econometric results in Section 5 show that social interaction effects are sufficiently strong to reconcile the aggregate enrollment patterns observed after a national policy reform with the downward-sloping demand curves found in earlier partial equilibrium analyses. That is, if we net out the change in public school pupil composition, we see that FPE did in fact increase effective demand for public schooling.

Our results suggest that social interactions may be an important source of general equilibrium effects from price reforms in the education system. Policies intended to promote equal access to primary schooling can have unintended consequences, as more affluent households attempt to disassociate themselves from marginal entrants responding to the price reform.

\section{References}

Acemoglu, Daron. 2010. "Theory, general equilibrium, and political economy in development economics." Journal of Economic Perspectives, 24(3): 1732 .

Ai, Chunrong, and Edward Norton. 2003. "Interaction terms in logit and probit models." Economics Letters, 80: 123-129.

Ashraf, Nava, James Berry, and Jesse Shapiro. 2010. "Can higher prices stimulate product use: Evidence from a field experiment in Zambia." American Economic Review.

Baron, Reuben M., and David A. Kennedy. 1986. "The moderator-mediator variable distinction in social psychological research: Conceptual, strategic, and statistical considerations." Journal of Personality and Social Psychology, 51: 1173-82.

Barrera-Osorio, Felipe, Leigh L. Linden, and Miguel Urquiola. 2007. "The effects of user fee reductions on enrollment: Evidence from a quasiexperiment." Columbia University.

Bayer, Patrick, and Christopher Timmins. 2007. "Estimating equilibrium models of sorting across locations." The Economic Journal, 117: 353 374.

Blume, Lawrence, and Steven Durlauf. 2005. "Identifying Social Interactions: A Review." Cornell University. 
Bold, Tessa, Mwangi Kimenyi, Germano Mwabu, and Justin Sandefur. 2011. "The high quality of low-cost private schools in a poor country." CSAE, Oxford University.

Cameron, A. Colin, and Pravin K. Trivedi. 2005. Microeconometrics: Methods and Applications. New York:Cambridge University Press.

Cheung, Maria, Andreas Madestam, and Jakob Svensson. 2011. "Who benefits from reduced cost of education? Evidence from a policy experiment in Cambodia." IIES, Stockholm University.

Cohen, Jessica, and Pascaline Dupas. 2010. "Free distribution or costsharing? Evidence from a randomized malaria prevention experiment." Quarterly Journal of Economics, 125: 1 - 45.

Cornelissen, Thomas, and Katja Sonderhof. 2009. "Partial effects in probit and logit models with a triple dummy variable interaction term." Stata Journal, 4(9): 571-583.

Deininger, Klaus. 2003. "Does cost of schooling affect enrollment by the poor? Universal primary education in Uganda." Economics of Education Review, 22: $291-305$.

DeLeire, Thomas. 2004. "Calculating Difference in Differences Using Probit Models versus Linear Probability Models." Note: Michigan State University.

Ellison, G, and E Glaeser. 1997. "Geographic concentration in U.S. maufacturing industries: A dartboard approach." Journal of Political Economy, 105: $889-927$.

Evans, David, Michael Kremer, and Muthoni Ngatia. 2009. "The impact of distributing school uniforms on children's education in Kenya." Poverty Action Lab, MIT.

Green, Donald P., Shang E. Ha, and John G. Bullock. 2010. "Enough Already about "Black Box" Experiments: Studying Mediation Is More Difficult than Most Scholars Suppose." Annals of the American Academic of Political and Social Science, 628: 200-208.

Gugerty, Mary Kay, and Edward Miguel. 2005. "Ethnic diversity, social sanctions, and public goods in Kenya." Journal of Public Economics, 89(11): $2325-68$. 
Imai, Kosuke, Luke Keele, Dustin Tingley, and Teppei Yamamoto. 2011. "Unpacking the Black Box: Learning about Causal Mechanisms from Experimental and Observational Studies." Princeton University.

Kremer, Michael, and Alaka Holla. 2009. "Pricing and access: Lessons from randomized evaluations in education and health." In What Works in Development: Thinking Big and Thinking Small. , ed. Jessica Cohen and William Easterly. Brookings Institution.

Lucas, Adrienne, and Isaac Mbiti. 2011. "The Effect of Free Primary Education on Student Participation, Stratification and Achievement: Evidence from Kenya." mimeo.

Muyanga, Milu Charles, John Olwande, Esther Mueni, and Stella Wambugu. 2010. "Free Primary Education in Kenya: An impact evaluation using propensity score methods." PMMA Working Paper 2010-08.

Nechyba, Thomas J. 2006. "Income and Peer Quality Sorting in Public and Private Schools." In Handbook of the Economics of Education. Vol. 2, , ed. E. Hanushek and F. Welch, Chapter 22, 1327-1368. Elsevier.

Norton, Edward. 2004. "Interaction Terms in Logit and Probit models." Presentation: UNC at Chapel Hill Academy Health.

Reber, Sarah. 2011. "From separate and unequal to integrated and equal? Desegration and school finance in Louisiana." The Review of Economics and Statistics, 93(2): 404-415.

Reinikka, Ritva, and Jakob Svensson. 2004. "Local Capture: Evidence From a Central Government Transfer Program in Uganda." The Quarterly Journal of Economics, 119(2): 678-704.

Schultz, T. Paul. 2004. "Subsidies for the poor: Evaluating the Mexican PROGRESA povert program." Journal of Development Economics, 74(1): 199250.

Sperling, Gene. 2008. "Hopes for democracy, stability and education alive in Kenya." Published online, Sept. 18, 2008, at http://www.huffingtonpost.com.

Teyie, Andrew, and Henry Wanyama. 2010. "Losses in FPE rise to Sh5.5 billion." Nairobi Star, 8 January. Available online at http://allafrica.com. 
Tooley, James. 2009. The Beautiful Tree: A Personal Journey Into How the World's Poorest People Are Educating Themselves. Cato Institute.

Wooldridge, Jeffrey M. 2001. Econometric analysis of cross section and panel data. MIT Press. 